SVU- International Journal of Veterinary Sciences, 3 (1): 1-9 , 2020.

Print ISSN: 2535-1826

Online ISSN: 2535-1877

CrossMark

Research Article

Open Access

\title{
Intrabursal Immunization as a Possible Route to Overcome Immunosuppression Due to Maternal Antibodies
}

\section{Rasha Radey*1, Elsayed S. I. Mohammed ${ }^{2}$, Mohamed S. Ahmed ${ }^{3}$}

${ }^{1}$ Animal Health Research Institute, Qena Laboratory, Qena, Egypt, ${ }^{2}$ Department of Histology and Cell Biology, Faculty of Veterinary Medicine, South Valley University, 83523, Qena, Egypt, ${ }^{3}$ Department of Poultry Diseases, Faculty of Veterinary Medicine, South Valley University, 83523, Qena, Egypt

Abstract

Vaccination is the most effective mean of preventing, controlling, and even eradicating infectious diseases. Poultry are vaccinated through various routes including eye/nose drops, drinking water, vent brush, or injections. The prolonged suppression effect of maternal antibodies on humoral immune response of newly hatched chicks to active immunization has been reported, while the effect of vaccination route on this suppression still unclear. Laying hens were immunized with dinitrophenyl-keyhole limpet hemocyanin (DNP-KLH). Purified maternal anti-DNP or non-specific IgY antibodies were transferred by yolk sac inoculation to newly hatched chicks (chicks of maternal and no-maternal antibodies), and they were immunized with DNP-KLH via intrabursal route at $0.1,1$ and $10 \mathrm{mg} / \mathrm{kg}$ body weight (BW) and with $1 \mathrm{mg} / \mathrm{kg} \mathrm{BW}$ intraperitoneally at 1 and 4 weeks of age. Concentration of anti-DNP antibodies in serum samples of these chicks was measured by using Enzyme- linked immunosorbent assay (ELISA). The immune response to intrabursal immunization was higher in chicks of no-maternal antibodies than that of chicks of maternal antibodies at 5 weeks of age. Intrabursal immunization showed higher response than intraperitoneal one at the same dose. These results confirmed that the immune suppressive effect of maternal antibodies on the immune response of the newly hatched chicks was antigen specific and depends on the ratio of antigen/maternal antibody at the time of immunization. Furthermore, intrabursal vaccination showed promising results than intraperitoneal vaccination at the same dose.

Keywords: Chick, IgY, Intrabursal vaccination, Maternal antibody, Suppression.

DOI: $10.21608 /$ svu.2019.17189.1030

Received: September 21, 2019 Accepted: November 02, 2019

Published: November 07, 2019

*Corresponding Author: Rasha Radey

E-mail: rradey@vet.svu.edu.eg

Citation: Radey et al., Intrabursal Immunization as a Possible Route to Overcome Immunosuppression Due to Maternal Antibodies. SVU-IJVS 2020, 3 (1): 1- 9.

Copyright: () Radey et al. This is an open access article distributed under the terms of the creative common attribution license, which permits unrestricted use, distribution and reproduction in any medium provided the original author and source are created.

Competing interest: The authors have declared that no competing interest exists. 


\section{Introduction}

Maternal antibodies play an important role in protection of the newly hatched chicks against various pathogens before the adaptive immune system is fully developed. However, it has been reported that the presence of high level of maternal antibodies can interfere or decrease the ability of the newly hatched chick to respond to an early vaccination (Chu and Rizk 1975; Goddard et al. 1994; Kumar et al., 2000; Bertran et al., 2018). Extended interference or immunosuppression of maternal antibodies on humoral immune response of the newly hatched chicks to active immunization has been studies (Elazab et al., 2008). Previous studies reported that maternal IgG down- regulates neonatal Ig synthesis (Klobasa et al., 1981; Elazab et al., 2010), possibly by elimination of environmental antigens in a similar way as intravenous immunoglobulin treatment or via a direct effect on B cells. Similar to chickens, in humans and mice, the effect of maternal antibodies on early life responses has been widely documented. Most studies indicate that the presence of maternal antibodies is responsible for weakness of infant primary antibody responses to both natural infections and vaccinations (Adkins et al., 2004). The immune suppressive effect of maternal antibodies on the humoral immune response of the newly hatched chicks is antigen specific and depends mainly on the ratio of antigen/maternal antibody at the time of immunization (Elazab et al., 2010). The suppression does not occur if the immunizing antigen is not closely related with the type of maternal antibody. Also, the suppression in humoral immune response is only observed when the chick received $8 \mathrm{mg}$ of anti-DNP antibodies and immunized with $2 \mathrm{mg}$ of DNP-KLH intraperitoneally (Elazab et al., 2010). Chick immunized intraperitoneally with high dose of DNP-KLH could show normal immune response against DNP; even they previously received $8 \mathrm{mg}$ of maternal anti-DNP antibodies (Elazab et al., 2010). The avian immune system is responsible for the humoral immune response and it consists primarily of the thymus, bursa of Fabricius, spleen, mucosa-associated lymphoid tissues, bone marrow and blood (Olah and Vervelde, 2008). The bursa of Fabricius is a hollow oval chestnut-like sac located dorsally to the cloaca, and it is unique for birds, and is considered as the site for B-cell lymphopoiesis, lymphocyte maturation, and differentiation and development of the humoral immune response. It has been reported that the bursa of Fabricius is an important link between the environmental antigens and the adaptive immune system to induce the formation of specific antibodies (Sorvari et al., 1975; Ekino et al., 1985; Taylor and McCorkle, 2009). Cloacal drinking or sucking reflex (uptake of particles by contractions of the cloaca) can expose the immune cells in the bursa of Fabricius to various antigens leading to the production of an antibody response (Sorvari et al., 1975). This is probably due to the very close physical relationship between the cloaca and the bursa and a reflex of the cloacal lips of chickens and turkeys that show a typical sucking response to touch or a drop of liquid (Schaffner et al., 1974 and 1976). Furthermore, Fluorescein labeled polystyrene beads (van der Sluis et al., 2009; Berghof et al., 2013) were taken up rapidly by the cloaca and transferred efficiently to the bursa. From the previous studies, it is possible to introduce an antigen to the bursa and therefore the purpose of this study is to evaluate the intrabursal immunization and the effect of the ratio of the antigen and the maternal antibodies on the immune response of the newly hatched chick. 


\section{Materials and Methods}

\section{Antigen preparation:}

A classical hapten-carrier antigen, Dinitrophenylated keyhole limpet hemocyanin (DNP-KLH) was used and prepared as previously described (Good et al., 1980; Furusawa et al., 1987; Elazab et al., 2010). Briefly, $200 \mathrm{mg}$ of K2CO3 was dissolved in $6 \mathrm{ml}$ of distilled water (DW) in a clean, dry and dark container, and then $200 \mathrm{mg}$ of KLH (Calbiochem Behring Co., Germany) was added slowly during stirring on a magnetic stirrer. At the same time, $200 \mathrm{mg}$ of 2, 4dinitrobenzen sulfonic acid sodium salt (DNBS) (Eastman Kodak Co., San Diego, USA) was dissolved in $4 \mathrm{ml}$ of DW. DNBS solution was added into KLH solution. Then, the mixture was stirred in dark place at room temperature for about 18 to 24 hours, and then dialyzed against phosphate buffered saline (PBP) at $4^{\circ} \mathrm{C}$ several times until optical density (OD) of the dialyzed buffer become zero at 360 $\mathrm{nm}$ against PBS. Finally, the mixture was sterilized by using $0.45 \mu \mathrm{m}$ filter. The protein concentration of this antigen was determined by OD value measured at 280 $\mathrm{nm}$. Conjugation ratio of hapten with protein was determined as described previously (Good et al., 1980; Furusawa et al., 1987). Final product was DNP32$\mathrm{KLH}$. Then, the antigen was kept in a refrigerator at $4^{\circ} \mathrm{C}$ until use.

\section{Animals:}

Partially inbred chickens (H-B15 white leghorn; Bu-1a) were used in this study. These chickens were bred in our animal facilities and were provided with feed and chlorinated water ad libitum under the regulation of guideline for the animal experiment in Hiroshima University. Eggs derived from the chickens were incubated and hatched in our own facilities. Chicks derived from non-immunized hens were ascertained to be free from maternal anti-DNP antibodies (Elazab et al., 2010).

\section{Immunization of laying hens:}

As previously prescribed by Akita and Nakai (1993) and Elazab et al. (2010), briefly, ten laying hens (1-2 years old) were immunized with DNP-KLH (1 mg per each hen) emulsified in Freund's complete adjuvant (FCA) (Wako Pure Chemical Industries, Japan) into their peritoneal cavity. Second immunization was performed after 2 weeks, then they repeatedly immunized every 3 weeks using Freund's incomplete adjuvant (FIA) (Wako Pure Chemical Industries, Japan). Eggs derived from immunized laying hens were collected daily after one week of the second immunization and stored in the refrigerator at $4^{\circ} \mathrm{C}$ until use for extraction of $\mathrm{IgY}$.

\section{Purification of chicken IgY:}

As previously described by Akita and Nakai (1993) and Elazab et al. (2010), briefly, Chicken IgY was extracted from the egg yolk by the water dilution method. The egg yolk was separated from the white and diluted 1:10 in DW and its $\mathrm{pH}$ value was adjusted to 5.2. Then the solution was kept in a refrigerator at $4^{\circ} \mathrm{C}$ for at least 6 hours. Then, mixed gently and centrifuged (centrifugation for 15 min. at $10,000 \mathrm{x} \mathrm{g}$ in a refrigerated centrifuge. The supernatant was decanted into a clean beaker, while stirring gently; ammonium sulfate (final percentage was $40 \%$ ) was added gently and the mixing was continued for at least 30 minutes. The suspension was centrifuged for $15 \mathrm{~min}$. at $10,000 \mathrm{x} \mathrm{g}$ in a refrigerated centrifuge. Supernatant was discarded. Equal volume of PBS to the original volume of the egg yolk was added to the pellet and mixed 
gently until IgY pellet was completely dissolved. Then, IgY solution was dialyzed for 4-5 times against PBS until ammonium sulfate would be completely removed. The volume of purified IgY solution was measured after filtration with $0.45 \mu \mathrm{m}$ filter.

\section{Inoculation of antibodies:}

A total number of 64 newly hatched chicks derived from non-immunized hens were used. Purified maternal anti-DNP antibody or non-specific $\operatorname{IgY}(200 \mu \mathrm{l}$ of $40 \mathrm{mg} / \mathrm{ml}$ in PBS) was injected into yolk sac of the newly hatched chicks divided in two groups ( $\mathrm{n}=32$ in each group) (directly after hatching) as described previously by Elazab et al. (2010).

The chicks were reared under ad libtium access to food and water. At 1 week of age the chicks in each group were subdivided into 4 subgroups according to antigen dose and route of immunization as follow:

1- Immunization of chicks of maternal and no-maternal antibodies $(\mathrm{n}=16$ chicks; 8 in each group) with $0.1 \mathrm{mg} / \mathrm{kg}$ BW DNP-KLH (intrabursal route)

2- Immunization of chicks of maternal and no-maternal antibodies $(\mathrm{n}=16$ chicks; 8 in each group) with $1 \mathrm{mg} / \mathrm{kg} \mathrm{BW}$ DNP-KLH (intrabursal route)

3- Immunization of chicks of maternal and no-maternal antibodies $(\mathrm{n}=16$ chicks; 8 in each group) with $10 \mathrm{mg} / \mathrm{kg}$ BW DNP-KLH (intrabursal route)

4- Immunization of chicks of maternal and no-maternal antibodies $(\mathrm{n}=16$ chicks; 8 in each group) with $1 \mathrm{mg} / \mathrm{kg} \mathrm{BW}$ DNP-KLH (intraperitoneal route)

The immunization was performed at one week (first immunization) and four weeks (second immunization) of age for all groups.

\section{Collection of blood:}

Blood samples were collected every week from each chick from the wing vein using $1 \mathrm{ml}$ syringe with $27 \mathrm{G}$ needle and stored at $4^{\circ} \mathrm{C}$ for 1 to 2 hours. Serum was separated from clotted blood by centrifugation at $10,000 \mathrm{x} \mathrm{g}$ for 5 minutes and stored at $-80^{\circ} \mathrm{C}$ until use.

\section{Enzyme-linked immunosorbent assay (ELISA):}

Concentration of anti-DNP antibodies was measured by ELISA as previously described (Yasuda et al., 1995).

\section{Statistical analysis:}

The mean of the concentration of anti-DNP antibodies in the chick's sera of maternal and no-maternal antibodies were compared using Tukey's test and Student's t-test. All values were expressed as mean \pm standard deviation and were considered to be significant at $\mathrm{p}<0.005$.

\section{Results}

\section{1- Chicks immunized via intrabursal route with DNP-KLH $0.1 \mathrm{mg} / \mathrm{kg} \mathrm{BW:}$}

In chicks of no-maternal antibodies, the concentration of anti-DNP antibodies in the serum did not show any significant difference after the first and second immunization. In chicks of maternal antibodies, the concentration of antiDNP antibodies decreased significantly from 1 week to 6 weeks of age regardless of immunization and this decrease did not show significant differences between 4, 5 and 6 weeks of age (Fig. 1). The concentration of antiDNP antibodies in the serum of chicks of maternal antibodies was significantly 
higher at 1, 2, 3, 4 and 5 weeks of age than that of chicks on no-maternal antibodies (Fig. 1).

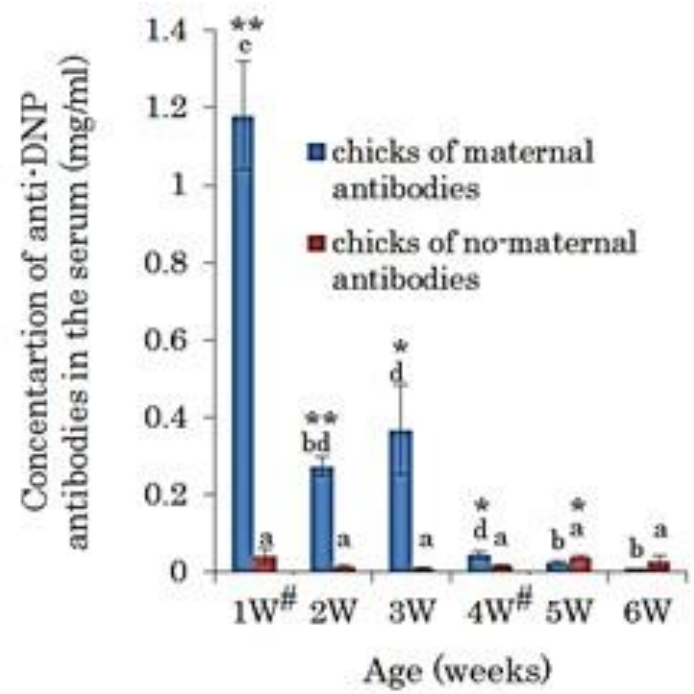

Fig. 1. Anti-DNP antibodies concentration in the serum of chicks of maternal and nomaternal antibodies immunized intrabursal with DNP-KLH $0.1 \mathrm{mg} / \mathrm{kg}$ BW. a,b,c,d Values are significantly different among the same treatment $(\mathrm{P}<$ 0.05, Tukey's test). ${ }^{*}$ Values are significantly different among different treatments at the same age $(\mathrm{P}<0.05$, Student's t-test). ${ }^{\#}$ Times of $1^{\text {st }}$ and $2^{\text {nd }}$ immunizations.

\section{2- Chicks immunized via intrabursal route with DNP-KLH 1 mg/kg BW:}

In chicks of no-maternal antibodies, the concentration of anti-DNP antibodies in the serum was significantly higher at 6 weeks of age than 2,3 and 4 weeks of age. The concentration of anti-DNP antibodies did not show differences from 1 week to 4 weeks of age (Fig. 2). The concentration of anti-DNP antibodies in the serum of chicks of maternal antibodies was significantly higher at 1 week than 2 , $3,4,5$ and 6 weeks of age. However, there were no significant differences between 2, 3, 4, 5 and 6 weeks of age (Fig. 2). The concentration of anti-DNP antibodies in the serum of chicks of maternal antibodies was significantly higher at 1 and 3 weeks of age than that of chicks on no-maternal antibodies (Fig. 2). In contrast, the concentration of anti-DNP antibodies in the serum of chicks of maternal antibodies was significantly lower than that of no-maternal antibodies at 5 weeks of age after the second immunization (Fig. 2).

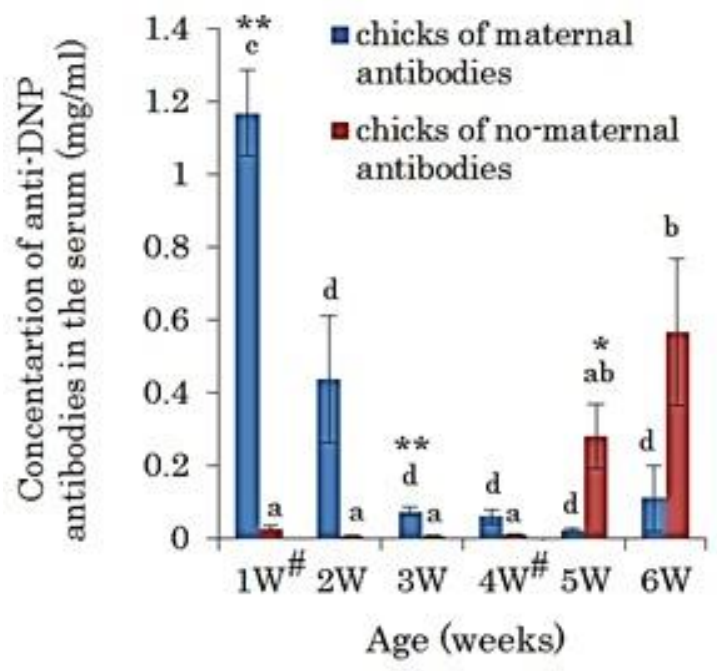

Fig. 2. Serum levels of anti-DNP antibodies in chicks of maternal and nomaternal antibodies immunized intrabursal with DNP-KLH $1 \mathrm{mg} / \mathrm{kg} \mathrm{BW}$. a,b,c,d Values are significantly different among the same treatment $(\mathrm{P}<0.05$, Tukey's test). ${ }^{*}$ Values are significantly different among different treatments at the same age $(\mathrm{P}<0.05$, Student's t-test). \# Times of $1^{\text {st }}$ and $2^{\text {nd }}$ immunizations.

\section{3- Chicks immunized via intraperitoneal route with DNP-KLH 1 mg/kg BW:}

In chicks of no-maternal antibodies, the concentration of anti-DNP antibodies in the serum was significantly higher at 5 weeks of age than 2, 3 and 4 weeks of age. The concentration of anti-DNP antibodies did not show differences from 1 week to 4 weeks of age (Fig. 3). The concentration of anti-DNP antibodies in the serum of chicks of maternal 
antibodies was significantly higher at 1 week than 2, 3, 4, 5 and 6 weeks of age. However, there were no significant differences between 2, 3, 4, 5 and 6 weeks of age (Fig. 3). The concentration of anti-DNP antibodies in the serum of chicks of maternal antibodies was significantly higher at $1,2,3$ and 4 weeks of age than that of chicks of nomaternal antibodies (Fig. 3). In addition, the concentration of anti-DNP antibodies in the serum of chicks of maternal antibodies did not show significant differences than that of no-maternal antibodies at 5 and 6 weeks of age after the second immunization (Fig. 3).

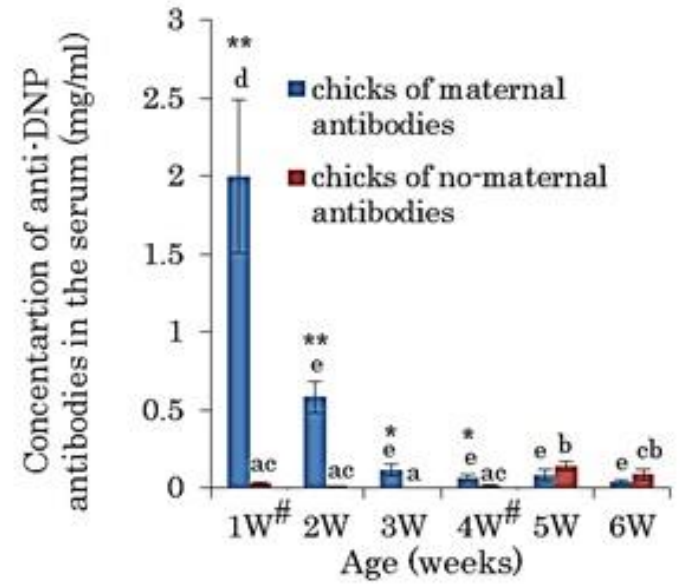

Fig. 3. Concentration of anti-DNP antibodies in the serum of chicks of maternal and no-maternal antibodies immunized intraperitoneal with DNPKLH $1 \mathrm{mg} / \mathrm{kg}$ BW. a,b,c,d,e Values are significantly different among the same treatment $(\mathrm{P}<0.05$, Tukey's test).

Values are significantly different among different treatments at the same age $(\mathrm{P}<$ 0.05 , Student's t-test). \# Times of $1^{\text {st }}$ and $2^{\text {nd }}$ immunizations.

\section{4- Chicks immunized via intrabursal route with DNP-KLH $10 \mathrm{mg} / \mathrm{kg} \mathrm{BW:}$}

In chicks of no-maternal antibodies, the concentration of anti-DNP antibodies in the serum was significantly higher at 6 weeks of age than 1,2, 3 and 4 weeks of age. The concentration of anti-DNP antibodies did not show differences from 1 week to 5 weeks of age (Fig. 4). The concentration of anti-DNP antibodies in the serum of chicks of maternal antibodies was significantly higher at 1 week than 2, 3, 4 and 5 weeks of age. However, there were no significant differences between 2, 3, 4, 5 and 6 weeks of age (Fig. 4). The concentration of anti-DNP antibodies in the serum of chicks of maternal antibodies was significantly higher at 1 weeks of age than that of chicks of no-maternal antibodies (Fig. 4). In contrast, the concentration of anti-DNP antibodies in the serum of chicks of no-maternal antibodies was significantly higher than that of maternal antibodies at 5 and 6 weeks of age after the second immunization (Fig. 4).

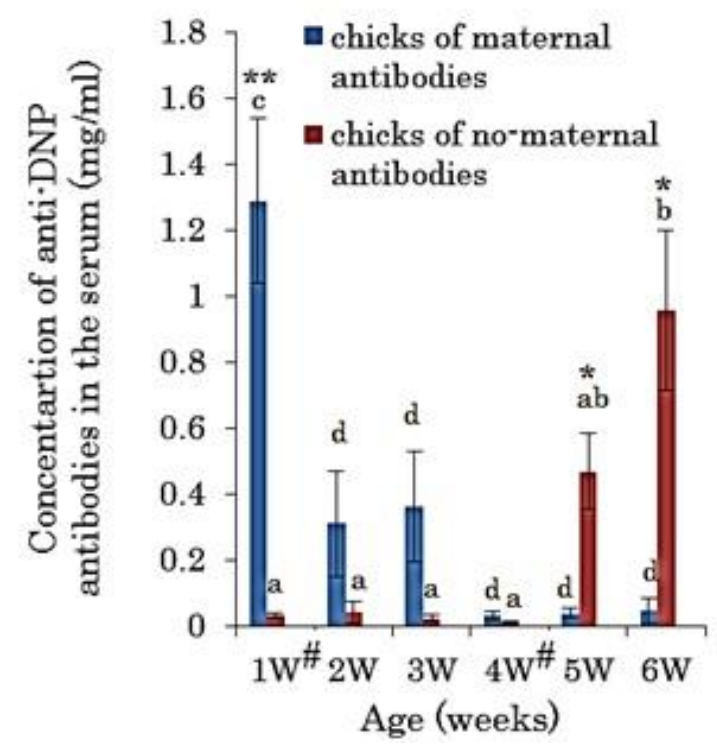

Fig. 4. Anti-DNP antibodies levels in the serum of chicks of maternal and nomaternal antibodies immunized intrabursal with DNP-KLH $10 \mathrm{mg} / \mathrm{kg}$ BW. a,b,c,d Values are significantly different among the same treatment $(\mathrm{P}<$ 0.05, Tukey's test). * Values are significantly different among different 
treatments at the same age $(\mathrm{P}<0.05$, Student's t-test). ${ }^{\#}$ Times of $1^{\text {st }}$ and $2^{\text {nd }}$ immunizations.

\section{Discussion}

This study reports the effects of intrabursal vaccination on the immune response in chicks with maternal and nomaternal antibodies. The major findings of this study are (1) the immune response of chicks vaccinated via intrabursal route was higher in chicks of no-maternal antibodies than that of chicks of maternal antibodies at 5 weeks; (2) in chicks vaccinated via intraperitoneal route, the response was not significant at 5 or 6 weeks of age between chicks of maternal and no-maternal antibodies; (3) these results confirmed that the immune suppressive effect of maternal antibodies on the immune response of the newly hatched chicks was antigen specific and depends on the ratio of antigen/maternal antibody at the time of immunization.

Staszewski et al. (2007) reported that maternal antibodies play an important role in protection of the hatchling against various environmental pathogens during the first few weeks of life that is required for the maturation of the immune system. The maternal antibodies have the ability to block circulating antigens (natural or vaccine-derived), thereby preventing disease or blocking early interaction with immune cells resulting in failure of immunization. In agreement to the previous reports, this study showed the immunosuppressive effect of maternal antibodies on the induction of humoral immune response to a normal level in either intrabursal or intraperitoneal immunization.

In our current study, the immune response of chicks vaccinated via intrabursal route was not as higher as previous report by Sorvari et al. (1975).
This difference may be due to that they used six consecutives daily intrabursal administrations of specific antigen in order to induce the measured high response in their study.

Although the immune response to intrabursal vaccination was not high and could not overcome the immunosuppressive effect of maternal antibodies or showed later higher responses at 6 weeks of age, it may affect the future challenge by pathogens or vaccinations as previously reported by Hughes and Henderson (1977). Hughes and Henderson (1977) reported that while using a certain dose of antigen for intrabursal immunization could not induce a measurable antibodies titer in the serum, it could generate an immunological memory for later antigenic challenge.

\section{Conflict of interest statement}

The authors declare that they have no conflict of interest.

\section{References}

Adkins B, Leclerc C, Marshall-Clarke S (2004). Neonatal adaptive immunity comes of age. Nature Review Immunology, 4: 553-564.

Akita EM, Nakai S (1993). Comparison of four purification methods for the production of immunoglobulin from eggs laid by hens immunized with an enterotoxigenic E.coli strain. Journal of Immunolological Methods. 160: 207-262.

Berghof TV, Lai HT, Lammers A, de Vries Reilingh G, Nieuwland MG, Aarnink AJ, Parmentier HK (2013). Localization and (semi)quantification of fluorescent beads of 2 sizes in chickens over time after simultaneous 
intratracheal and cloacal administration. Poultry Science, 92: 1186-1194.

Bertran K, Lee DH, Criado MF, Balzli CL, Killmaster LF, Kapczynski DR, DE Swayne (2018). Maternal antibody inhibition of recombinant Newcastle disease virus vectored vaccine in a primary or booster avian influenza vaccination program of broiler chickens. Vaccine, 36(43): 6361-6372.

Chu HP, Rizk J (1975). The effect of maternal immunity, age at vaccination and doses or live vaccines on immune response to Newcastle disease. Developments in biological standardization, 28: 451-463.

Ekino S, Suginohara K, Urano T, Fujii H, Matsuno K, Kotani M (1985). The bursa of Fabricius: a trapping site for environ- mental antigens. Immunology, 55: 405-410.

Elazab MFA, Fukushima Y, Fujita Y, Horiuchi H, Matsuda H, Furusawa $S$ (2010). Induction of immune suppression in the chick by an optimal dose of an immunizing antigen in the presence of its specific maternal antibody. Journal of Veterinary Medical Sciences, 72(3): 257-62.

Elazab MFA, Fukushima Y, Horiuchi H, Matsuda H, Furusawa S (2008). Prolonged suppression of chick humoral immune response by antigen specific maternal antibody. Journal of Vetertinary Medical Sciences, 71: 417-424.
Furusawa S, Okitsu-Negishi S, Yoshino K, Mizoguchi M, Noguchi Y (1987). Anti-idiotypic antibody as a mirror image of the paratope of the original antibody. International archives of allergy and applied immunology, 84: 263-270.

Goddard RD, Wyeth PJ, Varney WC (1994). Vaccination of commercial layer chicks against infectious bursal disease with maternally derived antibodies. Veterinary Record, 135: 273-2748.

Good AH, Wofsy L, Henry C, Kimura J (1980). Preparation of haptenmodified protein antigens. Selected methods in cellular immunology, 343-350

Hughes CL, Henderson DC (1977). Induction of avian immunological responsiveness following cloacal drinking of immunogen. Immunological Communications, 6: 195-206.

Klobasa F, Werhahn E, Butler JE (1981). Regulation of humoral immunity in the piglet by immunoglobulins of maternal origin. Research in Veterinary Science, 31: 195-206.

Kumar K, Singh KCP, Prasad CB (2000). Immune responses to intermediate strain IBD vaccine at different levels of maternal antibody in broiler chickens. Tropical Animal Health and Production, 32: 357-360.

Olah I, Vervelde L (2008). Structure of the avian lymphoid system. Academic Press, London. 
Poetri O, Bouma A, Claassen I, Koch G, Soejoedono R, Stegeman A, van Boven M (2011). A single vaccination of commercial broilers does not reduce transmission of H5N1 highly pathogenic avian influenza. Veterinary research, 42(1): 74 .

Schaffner T, Herring J, Gerber H, Cottier $\mathrm{H}$ (1976). Bursa of Fabricius: uptake of radioactive particles and radiotoxic "sealing" of bursal follicles. Advances in Experimental Medicine and Biology, 66: 33-39.

Schaffner T, Mueller J, Hess MW, Cottier H, Sordat B, Ropke C (1974). The bursa of Fabricius: a central organ providing for contact between the lymphoid system and intestinal content. Cellular Immunology, 13: 304-312.

Sorvari TR, Sorvari P, Ruotsalainen A Toivanen, Toivanen P (1975). Uptake of environmental antigens by the bursa of Fabricius. Nature, 253: 217-219.
Staszewski V, Gasparini J, Mccoy KD, Tveraa T, Boulinier T (2007). Evidence of an interannual effect of maternal immunization on the immune response of juveniles in a long-lived colonial bird. Journal of Animal Ecology, 76(6): 1215-23.

Taylor Jr RL, McCorkle Jr FM (2009). A landmark contribution to poultry science-Immunological function of the bursa of Fabricius. Poultry Science, 1;88(4): 816-23.

van der Sluis H J, Dwars RM, Vernooij JC, Landman WJ (2009). Cloacal reflexes and uptake of fluorescein- labeled polystyrene beads in broiler chickens. Poultry Science, 88: 1242-1249.

Yasuda M, Furusawa, S, Satoh A, Taura Y, Nakama S, Yoshihara K, Hirota Y (1995). Effects of 6hydroxydopamine on the antibody response to the hapten dinitrophenyl in the chicken. Journal of Veterinary Medical Sciences, 57: 1073-1075. 